\title{
CANONICAL DECOMPOSITION FOR DISSIPATIVE LINEAR RELATIONS
}

\author{
JosUÉ I. RIOS-CANGAS
}

Abstract. This work presents two ways of decomposing dissipative linear relations based on the fundamental decompositions for contractions by Sz. Nagy-Foiaş-Langer and von NeumannWold. The invariant subspaces for contractions are treated using a minor variation of the Cayley transform. The obtained decompositions allow one to separate the selfadjoint and completely nonselfadjoint parts of a dissipative relation.

Mathematics subject classification (2020): 47A06, 47B44, 47A45, 47A15.

Keywords and phrases: Dissipative linear relations, invariant and reducing subspaces, canonical decomposition.

\section{REFERENCES}

[1] Keshav Raj Acharya, Self-adjoint extension and spectral theory of a linear relation in a Hilbert space, ISRN Math. Anal. (2014), Art. ID 471640, 5. MR 3178945.

[2] N. I. AKhiEZer And I. M. Glazman, Theory of linear operators in Hilbert space, Dover Publications Inc., New York, 1993, Translated from the Russian and with a preface by Merlynd Nestell, Reprint of the 1961 and 1963 translations, Two volumes bound as one. MR 1255973 (94i:47001).

[3] Richard ARens, Operational calculus of linear relations, Pacific J. Math. 11 (1961), 9-23. MR 0123188 (23 \#A517).

[4] Aharon AtZmon, Unicellular and non-unicellular dissipative operators, Acta scientiarum mathematicarum 57 (1993), no. 1-4, 45-54, Bibliogr.: p. 53-54.

[5] T. Ya. Azizov, A. Dijksma, And G. Wanjala, Compressions of maximal dissipative and selfadjoint linear relations and of dilations, Linear Algebra Appl. 439 (2013), no. 3, 771-792. MR 3057107.

[6] Jussi Behrndt, Seppo Hassi, And Henk de Snoo, Boundary value problems, Weyl functions, and differential operators, Monographs in Mathematics, vol. 108, Birkhäuser/Springer, Cham, [2020] (C)2020. MR 3971207.

[7] Jussi Behrndt and Matthias Langer, Elliptic operators, Dirichlet-to-Neumann maps and quasi boundary triples, Operator methods for boundary value problems, London Math. Soc. Lecture Note Ser., vol. 404, Cambridge Univ. Press, Cambridge, 2012, pp. 121-160. MR 3050306.

[8] Jussi Behrndt, Matthias Langer, Vladimir LotoreichiK, and Jonathan Rohleder, Quasi boundary triples and semi-bounded self-adjoint extensions, Proc. Roy. Soc. Edinburgh Sect. A 147 (2017), no. 5, 895-916. MR 3705312.

[9] M. Sh. Birman AND M. Z. SolomjaK, Spectral theory of selfadjoint operators in Hilbert space, Mathematics and its Applications (Soviet Series), D. Reidel Publishing Co., Dordrecht, 1987, Translated from the 1980 Russian original by S. Khrushchëv and V. Peller. MR 1192782 (93g:47001).

[10] B. BRown, M. Marletta, S. NABOKo, AND IAN Wood, The functional model for maximal dissipative operators: An approach in the spirit of operator knots, Trans. Amer. Math. Soc. 373 (2020), 4145-4187 (2020).

[11] EARL A. CODDINGTON, Extension theory of formally normal and symmetric subspaces, American Mathematical Society, Providence, R. I., 1973, Memoirs of the American Mathematical Society, No. 134. MR 0477855.

[12] G. Corach, A. Maestripieri, And D. Stojanoff, Generalized Schur complements and oblique projections, Linear Algebra Appl. 341 (2002), 259-272, Special issue dedicated to Professor T. Ando. MR 1873624. 
[13] Ronald Cross, Multivalued linear operators, Monographs and Textbooks in Pure and Applied Mathematics, vol. 213, Marcel Dekker, Inc., New York, 1998. MR 1631548.

[14] Bruno DEsprés, Lise-MARIE IMBERT-GÉRARD, AND RiCARDO WEDER, Hybrid resonance of Maxwell's equations in slab geometry, J. Math. Pures Appl. (9) 101 (2014), no. 5, 623-659. MR 3192426.

[15] A. Dijksma And H. S. V. De Snoo, Self-adjoint extensions of symmetric subspaces, Pacific J. Math. 54 (1974), 71-100. MR 0361889 (50 \#14331).

[16] R. G. Douglas, On the operator equation $S^{*} X T=X$ and related topics, Acta Sci. Math. (Szeged) 30 (1969), 19-32. MR 0250106.

[17] Marco Falconi, Jérémy Faupin, JÜrg Fröhlich, And Baptiste Schubnel, Scattering theory for Lindblad master equations, Comm. Math. Phys. 350 (2017), no. 3, 1185-1218. MR 3607473.

[18] Mercedes Fernandez Miranda And Jean-Philippe Labrousse, The Cayley transform of linear relations, Proc. Amer. Math. Soc. 133 (2005), no. 2, 493-499. MR 2093073.

[19] AleXANDER Figotin AND AARON Welters, Dissipative properties of systems composed of highloss and lossless components, J. Math. Phys. 53 (2012), no. 12, 123508, 40. MR 3405898.

[20] CHRISTOPH FISCHBACHER, The nonproper dissipative extensions of a dual pair, Trans. Amer. Math. Soc. 370 (2018), no. 12, 8895-8920. MR 3864399.

[21] Christoph FischBACHER, SERGEy NABOKO, AND IAN WoOd, The proper dissipative extensions of a dual pair, Integral Equations Operator Theory 85 (2016), no. 4, 573-599. MR 3551233.

[22] PAul Richard Halmos, A Hilbert space problem book, second ed., Graduate Texts in Mathematics, vol. 19, Springer-Verlag, New York-Berlin, 1982, Encyclopedia of Mathematics and its Applications, 17. MR 675952.

[23] S. Hassi, Z. Sebestyén, H. S. V. de Snoo, and F. H. Szafraniec, A canonical decomposition for linear operators and linear relations, Acta Math. Hungar. 115 (2007), no. 4, 281-307. MR 2327982.

[24] Seppo Hassi, Mark Malamud, and Vadim Mogilevskit, Generalized resolvents and boundary triplets for dual pairs of linear relations, Methods Funct. Anal. Topology 11 (2005), no. 2, 170187. MR 2150518.

[25] I. S. KATS, Linear relations generated by canonical differential equations, Funktsional. Anal. i Prilozhen. 17 (1983), no. 4, 86-87. MR 725424.

[26] Thomas L. KRIETE, Canonical models and the self-adjoint parts of dissipative operators, J. Functional Analysis 23 (1976), no. 1, 39-94. MR 0433235.

[27] Carlos S. Kubrusly, An introduction to models and decompositions in operator theory, Birkhäuser Boston, Inc., Boston, MA, 1997. MR 1464436.

[28] Graeme W. Milton, Nicolae-Alexandru P. Nicorovici, Ross C. McPhedran, And ViKTOR A. PODOLSKIY, A proof of superlensing in the quasistatic regime, and limitations of superlenses in this regime due to anomalous localized resonance, Proc. R. Soc. Lond. Ser. A Math. Phys. Eng. Sci. 461 (2005), no. 2064, 3999-4034. MR 2186014.

[29] R. S. PHILlips, Dissipative operators and hyperbolic systems of partial differential equations, Trans. Amer. Math. Soc. 90 (1959), 193-254. MR 0104919.

[30] Heydar Radjavi and Peter Rosenthal, Invariant subspaces, second ed., Dover Publications, Inc., Mineola, NY, 2003. MR 2003221.

[31] Josué I. Rios-CAngas and Luis O. Silva, Dissipative extension theory for linear relations, Expo. Math. 38 (2020), no. 1, 60-90. MR 4082306.

[32] Josué I. Rios-Cangas And Luis O. Silva, Perturbation theory for selfadjoint relations, Ann. Funct. Anal. 11 (2020), no. 1, 154-170. MR 4091412.

[33] KonRAD SCHMÜDGEn, Unbounded self-adjoint operators on Hilbert space, Graduate Texts in Mathematics, vol. 265, Springer, Dordrecht, 2012. MR 2953553.

[34] B. M. Solomyak, A functional model for dissipative operators. A coordinate-free approach, Zap. Nauchn. Sem. Leningrad. Otdel. Mat. Inst. Steklov. (LOMI) 178 (1989), no. Issled. Lineĭn. Oper. Teorii Funktsiǔ. 18, 57-91, 184-185. MR 1037765.

[35] Laurian Suciu, Canonical decompositions induced by A-contractions, Note Mat. 28 (2008), no. 2, 187-202 (2010). MR 2681000.

[36] BÉla Sz.-Nagy, Sur les contractions de l'espace de Hilbert, Acta Sci. Math. Szeged 15 (1953), 87-92. MR 0058128. 
[37] Béla Sz.-NAgy, Ciprian Foias, Hari Bercovici, AND LÁszló KérChy, Harmonic analysis of operators on Hilbert space, second enlarged ed., Universitext, Springer, New York, 2010. MR 2760647.

[38] A. F. M. Ter Elst, Manfred Sauter, And Hendrik Vogt, a generalisation of the form method for accretive forms and operators, J. Funct. Anal. 269 (2015), no. 3, 705-744. MR 3350727.

[39] EKIN UĞURLU AND DUMitru BALEANU, On a completely non-unitary contraction and associated dissipative difference operator, J. Nonlinear Sci. Appl. 10 (2017), no. 11, 5999-6019. MR 3738818.

[40] Zhong Wang And Hongyou Wu, Dissipative non-self-adjoint Sturm-Liouville operators and completeness of their eigenfunctions, J. Math. Anal. Appl. 394 (2012), no. 1, 1-12. MR 2926200. 